\title{
Fatores genéticos e variabilidade na pressão arterial. Uma breve revisão da literatura.
}

\author{
Genetic factors and variability in blood pressure. \\ A brief literature review.
}

1 Universidade Federal do Paraná. Programa de Pós-Graduação em Educação Física. Curitiba, PR. Brasil.

2 Pontifícia Universidade Católica de Curitiba. Grupo de Pesquisa em Atividade Física e Qualidade de Vida. Curitiba, PR. Brasil.

3 Universidade do Porto. Faculdade de Desporto. Laboratório de Cineantropometria e Gabinete de Estatística Aplicada. Porto. Portugal.

Recebido em 03/01/07 Aprovado em 12/05/08
Resumo - O objetivo desta revisão foi abordar aspectos relacionados a importância dos fatores genéticos na variabilidade dos valores da pressão arterial. Foi realizada uma pesquisa na base de dados Pubmed e selecionados (1) estudos de agregação familiar com estimativas de heritabilidade, (2) estudos de linkage apenas com resultados significativos e (3) estudos de associação entre hipertensão arterial, genes candidatos e seus variantes alélicos, com base em delineamento de caso-controle. As estimativas de heritabilidade para a pressão arterial sistólica e diastólica variaram entre 14-68\% e 6-62\%, respectivamente. Foi verificado a presença de linkage para a pressão arterial sistólica nos cromossomas 2, 5, 6, 15 e 17. Os principais genes candidatos apresentaram resultados díspares na associação com a hipertensão. Conclui-se que a pressão arterial é um fenótipo poligênico, onde os fatores genéticos governam uma parte moderada a substancial da magnitude de sua variabilidade nas populações. Os genes candidatos identificados não explicam de modo suficientemente satisfatório a hipertensão arterial.

Palavras-chave: Epidemiologia Genética; Agregação Familiar; Heritabilidade; Linkage; Associação.

Abstract - The main purpose of this review was to gather relevant information regarding the importance of genetic factors for the variability of blood pressure levels. A search was performed in the Pubmed database, and the following studies were selected: (1) studies reporting familial aggregation with heritability estimates, (2) linkage studies reporting only significant results, and (3) association studies between blood pressure, candidate genes and their allelic variants using a case-control design. Heritability estimates for systolic and diastolic blood pressure ranged from 14 to $68 \%$ and from 6 to $62 \%$, respectively. We found significant linkage results for systolic blood pressure on chromosomes 2, 5, 6, 15 and 17. Relevant candidate genes presented disparate results in terms of their association with arterial hypertension. Blood pressure is a polygenic phenotype whose variation is partially mediated by genetic factors. The candidate genes identified do not sufficiently explain arterial hypertension.

Key words: Genetic epidemiology; Familial aggregation; Heritability; Linkage; Association. 


\section{INTRODUÇÃO}

A pressão arterial (PA) é um parâmetro fisiológico determinado pela razão entre o débito cardíaco e a resistência periférica, que pode ser aumentada por elevações em uma ou em ambas as variáveis ${ }^{1}$. Devido ao fato do risco de mortalidade aumentar progressivamente com a elevação da PA a partir de $115 / 75 \mathrm{mmHg}$, seu incremento apresenta um importante fator de risco independente, linear e contínuo para o desenvolvimento das doenças

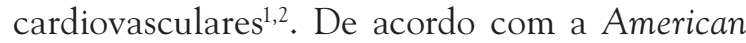
Heart Association ${ }^{2}$, a hipertensão arterial (HA) é um dos principais problemas de saúde pública e a doença mais comum em países industrializados. Estima-se que um a cada três norte-americanos seja hipertenso ${ }^{2}$.

Existe um conjunto de causas potencialmente determinantes para a ocorrência da HA, no qual se destacam a idade, a obesidade, os hábitos alimentares inadequados, o tabagismo, a inatividade física e os fatores genéticos, entre outros ${ }^{1,2}$. Na etiologia dessa doença, sabe-se que a influência familiar possui uma forte contribuição na manifestação final dos valores da PA. Assim, a HA é classificada como uma doença genética complexa e que na maioria dos casos é o resultado final da interação entre fatores genéticos, ambientais e demográficos ${ }^{3}$. Alguns estudos realizados em famílias evidenciaram que os fatores genéticos podem ser responsáveis por até $68 \%{ }^{4}$ dos valores da PA sistólica (PAS) e $62 \%{ }^{5}$ da PA diastólica (PAD).

Devido ao alto grau de complexidade da HA e partindo do pressuposto que a variação interindividual dos valores da PA são, em parte, determinados geneticamente, algumas abordagens vêm sendo utilizadas para identificar os genes que participam da origem da hipertensão. De acordo com Gonçalves ${ }^{3}$, uma das estratégias mais utilizadas para tentar identificar o locus genético com a predisposição para o desenvolvimento dessa doença é a investigação com genes candidatos. Essa estratégia baseia-se no princípio de que um ou mais genes, envolvidos em funções fisiológicas específicas, contribuem para a variação da PA. Alguns genes que têm sido estudados com o auxílio desta técnica são os do sistema renina-angiotensina (ACE, AGT e ATR1) 3

Com base nessas informações, o objetivo deste estudo foi realizar uma revisão da literatura acerca da importância dos fatores genéticos na variabilidade dos valores da PA.

\section{MÉTODOS}

Foi realizada uma pesquisa na base de dados Pubmed por meio de estratégia de busca com os termos Familial Aggregation, Heritability, Genetic Study, Linkage Analysis, Association, Blood Pressure, Hypertension e suas possíveis combinações. $\mathrm{O}$ critério de inclusão para as referências ocorreu da seguinte maneira: (1) para as pesquisas de agregação familiar foram selecionados os estudos com estimativas de heritabilidade $\left(\mathrm{h}^{2}\right)$ a partir de 1996, provenientes de diferentes países e com base no delineamento de famílias nucleares e/ou pedigrees extensos; (2) para as pesquisas de linkage, foram selecionados apenas os estudos com resultados significativos em um ou mais cromossomas e (3) para os estudos de associação genética entre $\mathrm{HA}$, genes candidatos e seus variantes alélicos, foram selecionadas as evidências mais recentes com base em delineamento de caso-controle.

\section{RESULTADOS}

\section{Estudos de Agregação Familiar}

Diversas pesquisas realizadas com famílias em diferentes países salientaram a presença de agregação familiar nos valores da PA (Quadro 1). Dos 21 estudos que atenderam os critérios de inclusão, quatro foram realizados em populações européias ${ }^{6-9}$, 11 na população norte-americana ${ }^{4,10-19}$, quatro em populações asiáticas ${ }^{5,20-22}$, um na população africa$\mathrm{na}^{23}$ e um na população da Oceania ${ }^{24}$.

Na população européia as estimativas de $h^{2}$ para a PAS e a PAD variaram entre $0,14^{7}$ a $0,51^{8} \mathrm{e}$ $0,06^{9}$ a $0,30,{ }^{6}$ respectivamente. A população norteamericana apresentou valores de contribuição genética para a PAS que variaram entre $0,16^{14}$ a 0,684 $\mathrm{e}$ para a PAD entre $0,21^{15}$ a $0,56^{4,18}$. Estudos realizados em populações asiáticas apresentaram contribuições genéticas entre $0,19^{22}$ a $0,55^{5}$ e 0,0922 a 0,625 para a PAS e PAD, respectivamente. Na população africana as estimativas de $h^{2}$ encontradas foram de 0,45 e 0,43 para a PAS e PAD, respectivamen$\mathrm{te}^{23}$. Uma pesquisa realizada com a população da Oceania com 1319 famílias nucleares australianas encontrou $\mathrm{h}^{2}=0,27$ para a PAS e a $\mathrm{PAD}^{24}$.

\section{Estudos de Linkage}

Os resultados obtidos através das estimativas de $\mathrm{h}^{2}$ indicam que os fatores genéticos governam, em parte, a variabilidade dos valores da PA no seio das famílias. Essas informações tornam-se imprescindíveis para dar sequência às etapas da pesquisa em epidemiologia genética. 
Quadro 1. Metodologia e resultados dos estudos com base na estimativa de heritabilidade ( $h^{2} \pm$ erro padrão) na variabilidade nos níveis da pressão arterial agrupados de acordo com a população estudada.

\begin{tabular}{|c|c|c|c|c|c|c|}
\hline \multirow{3}{*}{ População } & \multirow{3}{*}{$\begin{array}{l}\text { Autorref, } \\
\text { País }\end{array}$} & \multirow{3}{*}{ Propósito } & \multirow{3}{*}{ Amostra } & \multirow{3}{*}{$\begin{array}{l}\text { Delinea- } \\
\text { mento }\end{array}$} & \multirow{2}{*}{\multicolumn{2}{|c|}{$\frac{\text { Principais resultados }\left(\mathrm{h}^{2}\right)}{\text { Fenótipos }}$}} \\
\hline & & & & & & \\
\hline & & & & & PAS & PAD \\
\hline \multirow{4}{*}{ Européia } & $\begin{array}{l}\text { Saunders } \\
\text { et } \mathrm{al}^{9} \\
\text { Inglaterra }\end{array}$ & $\begin{array}{l}\text { Estimar a } h^{2} \text { dos FatR das } \\
\text { DCV (PAS, PAD IMC, } \\
\text { RCQ C-HDL, C-total) }\end{array}$ & $\begin{array}{l}17690 \text { indivíduos indivíduos } \\
\text { pertencentes a } 6183 \text { famílias }\end{array}$ & $\begin{array}{l}\text { Famílias } \\
\text { nucleares }\end{array}$ & $0,18 \pm 0,06$ & $0,06 \pm 0,05$ \\
\hline & $\begin{array}{l}\text { Mills et al } \\
\text { Inglaterra }\end{array}$ & $\begin{array}{c}\text { Estimar a } h^{2} \text { dos compo- } \\
\text { nentes da SM } \\
(\underline{P A S}, \underline{P A D}, I M C, T G \\
\text { C-HDL, GL, RCQ) }\end{array}$ & $\begin{array}{l}811 \text { indivíduos adultos perten- } \\
\text { centes a } 278 \text { famílias }\end{array}$ & $\begin{array}{l}\text { Famílias } \\
\text { nucleares }\end{array}$ & 0,29 & 0,30 \\
\hline & $\begin{array}{l}\text { Freeman } \\
\text { et } \mathrm{al}^{7} \\
\text { Inglaterra }\end{array}$ & $\begin{array}{l}\text { Estimar a } h^{2} \text { dos compo- } \\
\text { nentes da SM (PAS, IMC, } \\
\text { TG, C-HDL, GL, RCQ) }\end{array}$ & $\begin{array}{c}537 \text { indivíduos pertencentes a } \\
89 \text { famílias } \\
217 \sigma^{7}(41,9 \pm 16,1 \text { anos }) \text { e } 320 \text { 우 } \\
(44,1 \pm 16,8 \text { anos })\end{array}$ & $\begin{array}{c}\text { Pedigrees } \\
\text { extensos }\end{array}$ & 0,14 & - \\
\hline & $\begin{array}{l}\text { Livshits } \\
\text { e Gerber } \\
\text { Rússia }\end{array}$ & $\begin{array}{c}\text { Estimar a } \mathrm{h}^{2} \text { da } \underline{\mathrm{PAS}} \mathrm{e} \\
\underline{\mathrm{PAD}}\end{array}$ & $\begin{array}{c}514 \text { indivíduos pertencentes a } \\
135 \text { famílias } \\
\text { Pais: } 115 \sigma^{\top}(63,6 \pm 6,1 \text { anos }) \text { e } \\
122 \text { 우 }(62,9 \pm 5,9 \text { anos }) \\
\text { Filhos: } 178 \sigma^{\top}(34,4 \pm 9,9 \text { anos }) \text { e } \\
\text { 122우 }(36,6 \pm 10,4 \text { anos })\end{array}$ & $\begin{array}{l}\text { Famílias } \\
\text { nucleares }\end{array}$ & $0,51 \pm 0,13$ & $0,20 \pm 0,09$ \\
\hline \multirow{10}{*}{$\begin{array}{l}\text { Norte } \\
\text { Americana }\end{array}$} & $\begin{array}{l}\text { Butte et al }{ }^{10} \\
\text { EUA }\end{array}$ & $\begin{array}{c}\text { Estimar a } h^{2} \text { dos com- } \\
\text { ponentes da SM (PAS, } \\
\text { PerCint, TG, C-HDL, GL) }\end{array}$ & $\begin{array}{c}600 \text { pais e } 1030 \text { crianças (4-19 } \\
\text { anos) pertencentes a } \\
319 \text { famílias de origem mexi- } \\
\text { cana do } \\
\text { Viva La Família Study }\end{array}$ & $\begin{array}{l}\text { Pedigrees } \\
\text { extensos }\end{array}$ & $0,32 \pm 0,07$ & - \\
\hline & $\begin{array}{l}\text { North et } \\
\text { al }^{11} \text { EUA }\end{array}$ & $\begin{array}{l}\text { Estimar a } \mathrm{h}^{2} \text { dos FatR } \\
\text { das DCV }(\underline{P A S}, \underline{P A D}, \\
\text { PerCint, TG, C-HDL, } \\
\quad \text { C-LDL, IMC) }\end{array}$ & $\begin{array}{l}950 \text { indivíduos adultos perten- } \\
\text { centes a } 32 \text { famílias participan- } \\
\text { tes do The Strong Heart Family } \\
\text { Study }\end{array}$ & $\begin{array}{l}\text { Pedigrees } \\
\text { extensos }\end{array}$ & $0,23 \pm 0,06$ & $0,34 \pm 0,07$ \\
\hline & $\begin{array}{l}\text { Liu et } \mathrm{al}^{12} \\
\text { EUA }\end{array}$ & 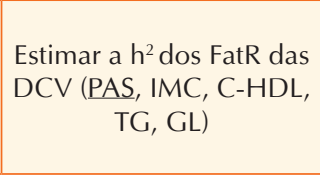 & $\begin{array}{l}2117 \text { indivíduos adultos perten- } \\
\text { centes a } \\
330 \text { famílias caucasianas parti- } \\
\text { cipantes do } \\
\text { The Framingham Heart Study }\end{array}$ & $\begin{array}{l}\text { Pedigrees } \\
\text { extensos }\end{array}$ & $0,24 \pm 0,04$ & - \\
\hline & $\begin{array}{l}\text { McQueen } \\
\text { et al }{ }^{13} \\
\text { EUA }\end{array}$ & $\begin{array}{c}\text { Estimar a } h^{2} \text { dos compo- } \\
\text { nentes da SM (PAS, IMC, } \\
\text { TG, C-HDL, GL) }\end{array}$ & $\begin{array}{l}1617 \text { indivíduos adultos (30-69 } \\
\text { anos) de } \\
\text { origem caucasiana participan- } \\
\text { tes do } \\
\text { The Framingham Heart Study }\end{array}$ & $\begin{array}{l}\text { Pedigrees } \\
\text { extensos }\end{array}$ & 0,48 & - \\
\hline & $\begin{array}{l}\text { Martin } \\
\text { et al }{ }^{14} \\
\text { EUA }\end{array}$ & $\begin{array}{l}\text { Estimar a } \mathrm{h}^{2} \text { dos compo- } \\
\text { nentes da SM (PAS, IMC, } \\
\text { TG, C-HDL, C-total) }\end{array}$ & $\begin{array}{l}1648 \text { indivíduos adultos } \\
\text { pertencentes a } 330 \text { famílias } \\
\text { participantes do The Framin- } \\
\text { gham Heart Study }\end{array}$ & $\begin{array}{l}\text { Pedigrees } \\
\text { extensos }\end{array}$ & $0,16 \pm 0,35$ & - \\
\hline & $\begin{array}{l}\text { Camp } \\
\text { et al }{ }^{15} \\
\text { EUA }\end{array}$ & $\begin{array}{l}\text { Estimar } \mathrm{h}^{2} \text { da } \underline{\mathrm{PAS}}, \underline{\mathrm{PAD}} \mathrm{e} \\
\text { pressão de pulso }\end{array}$ & $\begin{array}{c}2444 \text { indivíduos adultos per- } \\
\text { tencentes a } 98 \text { famílias } 1304 \\
\text { Љ }(26,5 \pm 18,1 \text { anos }) \text { e } 1140 \text { 우 } \\
(29,3 \pm 18,2 \text { anos })\end{array}$ & $\begin{array}{l}\text { Pedigrees } \\
\text { extensos }\end{array}$ & 0,19 & 0,21 \\
\hline & $\begin{array}{l}\text { Cheng } \\
\text { et al }{ }^{16} \\
\text { EUA }\end{array}$ & $\begin{array}{c}\text { Estimar } h^{2} \text { da PAS, } \\
\underline{\text { PAD e IMC }}\end{array}$ & $\begin{array}{c}390 \text { indivíduos adultos } \\
(55,7 \pm 8,6 \text { anos) pertencentes a } \\
77 \text { famílias de origem hispânica }\end{array}$ & $\begin{array}{l}\text { Famílias } \\
\text { nucleares }\end{array}$ & $0,64 \pm 0,14$ & $0,34 \pm 0,14$ \\
\hline & $\begin{array}{l}\text { Hsueh } \\
\text { et al }{ }^{17} \\
\text { EUA }\end{array}$ & $\begin{array}{c}\text { Estimar a } h^{2} \text { dos FatR } \\
(\underline{\text { PAS }}, \underline{\text { PAD }}, I M C, \text { PerCint, } \\
\text { TG, C-HDL, C-total, GL) }\end{array}$ & $\begin{array}{l}953 \text { indivíduos adultos perten- } \\
\text { centes a } 45 \text { famílias partici- } \\
\text { pantes do The Amish Family } \\
\text { Diabetes Study } \\
\text { Pais: } 35-65 \text { anos } \\
\text { Filhos: } \geq 18 \text { anos }\end{array}$ & $\begin{array}{l}\text { Pedigrees } \\
\text { extensos }\end{array}$ & $0,18 \pm 0,06$ & $0,24 \pm 0,07$ \\
\hline & $\begin{array}{l}\text { Levy et al }{ }^{18} \\
\text { EUA }\end{array}$ & $\begin{array}{c}\text { Estimar a } h^{2} \text { da } \underline{\text { PAS }} \text { e } \\
\text { PAD }\end{array}$ & $\begin{array}{l}1593 \text { famílias participantes do } \\
\text { The Framingham Heart Study }\end{array}$ & $\begin{array}{l}\text { Pedigrees } \\
\text { extensos }\end{array}$ & 0,57 & 0,56 \\
\hline & $\begin{array}{l}\text { An et al }{ }^{19} \\
\text { EUA }\end{array}$ & Estimar a $h^{2}$ da $\underline{P A}$ e FC & $\begin{array}{l}552 \text { indivíduos pertencentes a } \\
98 \text { famílias } \\
\text { participantes do The HERITAGE } \\
\text { Family Study } \\
257 \text { ð e 265우 (17-65 anos) }\end{array}$ & $\begin{array}{l}\text { Famílias } \\
\text { nucleares }\end{array}$ & 0,51 & 0,42 \\
\hline
\end{tabular}

continua $\downarrow$ 


\begin{tabular}{|c|c|c|c|c|c|c|}
\hline \multirow{3}{*}{ População } & \multirow{3}{*}{$\begin{array}{l}\text { Autoref } \\
\text { País }\end{array}$} & \multirow{3}{*}{ Propósito } & \multirow{3}{*}{ Amostra } & \multirow{3}{*}{$\begin{array}{l}\text { Delinea- } \\
\text { mento }\end{array}$} & \multirow{2}{*}{\multicolumn{2}{|c|}{\begin{tabular}{|c} 
Principais resultados $\left(\mathrm{h}^{2}\right)$ \\
Fenótipos
\end{tabular}}} \\
\hline & & & & & & \\
\hline & & & & & PAS & PAD \\
\hline $\begin{array}{l}\text { Norte } \\
\text { Americana }\end{array}$ & $\begin{array}{l}\text { Gu et al }{ }^{4} \\
\text { EUA }\end{array}$ & $\begin{array}{c}\text { Estimar a } h^{2} \text { da PAS e } \\
\underline{P A D}\end{array}$ & 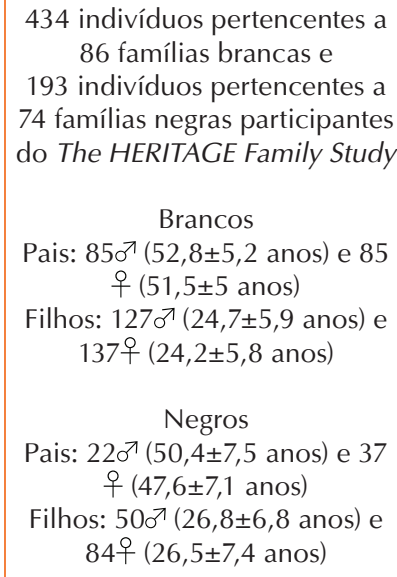 & $\begin{array}{l}\text { Famílias } \\
\text { nucleares }\end{array}$ & $\begin{array}{l}0,43^{\ddagger} \\
0,68^{\S} \\
0,46^{\square}\end{array}$ & $\begin{array}{l}0,24^{\ddagger} \\
0,56^{\S} \\
0,31\end{array}$ \\
\hline \multirow{4}{*}{ Asiática } & $\begin{array}{l}\text { Chien } \\
{\text { et a } 2^{20}}^{\text {China }}\end{array}$ & $\begin{array}{c}\text { Estimar a } h^{2} \text { dos compo- } \\
\text { nentes da SM } \\
\text { (PAS, PAD, IMC, PerCint, } \\
\text { TG, C-HDL, GL) }\end{array}$ & $\begin{array}{c}1356 \text { indivíduos participantes } \\
\text { do } \\
\text { The Chin-Shan Community } \\
\text { Family Study } \\
\text { Adultos: } 300 \sigma^{\top} \text { e 353우 } \\
\text { Adolescentes: } 342 \delta^{7} \text { e 361우 }\end{array}$ & $\begin{array}{c}\text { Pedigrees } \\
\text { extensos }\end{array}$ & $0,32 \pm 0,06$ & $0,23 \pm 0,08$ \\
\hline & $\begin{array}{l}\text { Li et al }{ }^{5} \\
\text { China }\end{array}$ & $\begin{array}{c}\text { Estimar a } h^{2} \text { dos compo- } \\
\text { nentes da SM } \\
\text { (PAS, PAD, IMC, PerCint, } \\
\text { TG, C-HDL, GL) }\end{array}$ & $\begin{array}{l}913 \text { indivíduos (25-54 anos) } \\
\text { pertencentes } \\
\text { a } 179 \text { famílias participantes do } \\
\text { The Hong Kong Family Diabe- } \\
\text { tes Study }\end{array}$ & $\begin{array}{l}\text { Pedigrees } \\
\text { extensos }\end{array}$ & $0,55 \pm 0,08$ & $0,62 \pm 0,08$ \\
\hline & $\begin{array}{l}\text { Ng et a }{ }^{21} \\
\text { China }\end{array}$ & $\begin{array}{l}\text { Estimar a } \mathrm{h}^{2} \text { dos compo- } \\
\text { nentes da SM }(\text { PAS, PAD, } \\
\text { PerCint, TG, C-HDL) }\end{array}$ & $\begin{array}{l}137 \text { indivíduos pertencentes a } \\
55 \text { famílias do } \\
\text { The Hong Kong Family Diabe- } \\
\text { tes Study } \\
580^{7} \text { e } 79 \text { 우 ( } 43 \pm 9 \text { anos) }\end{array}$ & $\begin{array}{l}\text { Pedigrees } \\
\text { extensos }\end{array}$ & \multicolumn{2}{|c|}{$0,45-0,63^{\text {m }}$} \\
\hline & $\begin{array}{l}\text { Jee et al }{ }^{22} \\
\text { Coréia do } \\
\text { Sul }\end{array}$ & $\begin{array}{c}\text { Estimar a } \mathrm{h}^{2} \text { dos FatR } \\
\text { das DCV (PAS, } \underline{\text { PAD }}, \\
\text { IMC, C-total) }\end{array}$ & 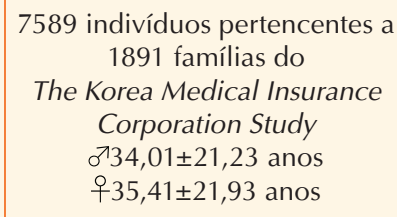 & $\begin{array}{l}\text { Famílias } \\
\text { nucleares }\end{array}$ & $\begin{array}{l}0,19 \pm \\
0,014\end{array}$ & $\begin{array}{l}0,09 \pm \\
0,008\end{array}$ \\
\hline Oceania & $\begin{array}{l}\text { Knuiman } \\
\text { et al }{ }^{24} \\
\text { Austrália }\end{array}$ & $\begin{array}{c}\text { Estimar a } h^{2} \text { dos FatR } \\
\text { das DCV (PAS, PAD, } \\
\text { IMC, C-total) }\end{array}$ & $\begin{array}{c}4178 \text { indivíduos adultos perten- } \\
\text { centes a } 1319 \text { famílias } \\
\text { Pais: } 8810^{\top}(55 \pm 11 \text { anos) e } 1068 \\
\text { o ( } 54 \pm 11 \text { anos) } \\
\text { Filhos: } 11080^{7}(34 \pm 13 \text { anos) e } \\
1121 \text { ( }(35 \pm 14 \text { anos) }\end{array}$ & $\begin{array}{l}\text { Famílias } \\
\text { nucleares }\end{array}$ & 0,27 & 0,27 \\
\hline Africana & $\begin{array}{l}\text { Rotimi } \\
\text { et a }{ }^{23} \\
\text { Nigéria }\end{array}$ & $\begin{array}{c}\text { Estimar a } h^{2} \text { da PAS e } \\
\underline{P A D}\end{array}$ & $\begin{array}{c}1552 \text { indivíduos pertencentes a } \\
510 \text { famílias } \\
\text { Pais: } 320 \sigma^{7}(56 \pm 9,2 \text { anos) e } 370 \\
\text { + }(50,3 \pm 10 \text { anos }) \\
\text { Filhos: } 475 \sigma^{7}(26,2 \pm 13 \text { anos) e } \\
387+\text { P }(25,9 \pm 12,3 \text { anos })\end{array}$ & $\begin{array}{l}\text { Famílias } \\
\text { nucleares }\end{array}$ & 0,45 & 0,43 \\
\hline
\end{tabular}

FatR: fatores de risco, DCV: doenças cardiovasculares, PAS: pressão arterial sistólica, PAD: pressão arterial diastólica, IMC: índice de massa corporal, RCQ: relação cintura-quadril, C-HDL: colesterol - high density lipoproteins, C-total: colesterol total, SM: síndrome metabólica, TG: triglicerídios, GL: glicemia, HA: hipertensão arterial, PerCint: perímetro da cintura, C-LDL: colesterol - low density lipoproteins, FC: frequência cardíaca, ^: brancos, s: negros, l: brancos e negros, ": $\mathrm{h}^{2}$ dos fenótipos PAS, PAD, PerCint, TG e C-HDL. 
Tabela 1. Metodologia e resultados de dois estudos que apresentaram linkage significativo em cromossomas, para a pressão arterial sistólica, com os respectivos marcadores e posições.

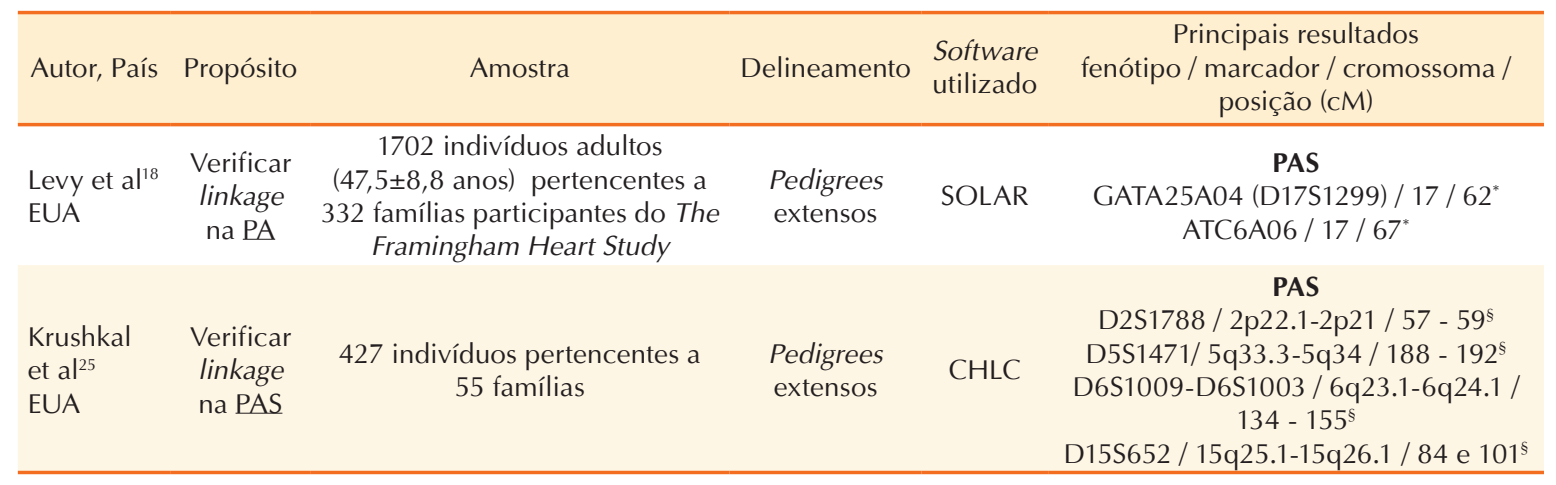

PA: pressão arterial, *: presença de linkage (lod score >3), PAS: pressão arterial sistólica, s: presença de linkage com base no valor de $p$.

Foram encontrados 14 estudos com base em genome wide scan que procuraram verificar a presença de linkage em diversos cromossomas, afim de identificar regiões responsáveis (e seus genes candidatos) pela variabilidade dos valores da PA. Contudo, somente duas pesquisas referenciaram a presença de linkage significativo (lod score $>3$ ) para a PAS nos cromossomas 2 (2p22.1-2p21), 5 (5q33.3. 5q34), 6 (6q23.1-6q24.1), 15 (15q25.1-15q26.1) $)^{25}$ e 17 $(17 \mathrm{q} 12-21)^{18}$ onde possivelmente poderão se situar os genes responsáveis pelo controle desta componente da PA (Tabela 1).

\section{Estudos de Associação}

As pesquisas na área da genética molecular procuram associar determinadas variações na sequência de DNA (aqui referenciados por alelos) em genes candidatos que se especula regularem a PA (Quadro 2).

\section{DISCUSSÃO}

Esse estudo teve como objetivo realizar uma revisão da literatura acerca da importância dos fatores genéticos na variabilidade dos valores da PA. A detecção e a avaliação da agregação familiar são os primeiros passos na análise genética de qualquer característica externa apresentada por um indivíduo. De um modo geral, os resultados são consistentes ao referirem que uma parte moderada a elevada da variabilidade populacional da PA, subdividida em suas duas componentes (PAS e PAD), é condicionada por fatores genéticos. Em nove ${ }^{4,5,8,13,16,18,19,21,23}$ dos 21 estudos selecionados, os valores de $h^{2}$ foram superiores a 0,45. Contudo, observa-se uma ampla variabilidade nas estimativas de $\mathrm{h}^{2}$ entre os estudos. É importante salientar que além do fato da PA ser um fenótipo poligênico, influenciado por um gran- de número de fatores que pode possuir mecanismos genéticos diferenciados em populações distintas, a discrepância observada pode ser devida, também, às diferenças na dimensão amostral, aspectos étnicos e culturais inerentes a cada população e o design de pesquisa.

Apesar de ter sido encontrada a presença de linkage para a PAS em alguns cromossomas $(2,5,6$, $15^{25} \mathrm{e} 17^{18}$ ), onde possivelmente poderão se situar os genes responsáveis pelo controle dessa componente da PA, Martin et $\mathrm{al}^{14} \mathrm{e} \mathrm{Ng}$ et $\mathrm{a}^{21}$ não a verificaram em nenhum dos 22 pares de cromossomas. Da mesma maneira, tanto para a PAD quanto para a HA, nenhum dos estudos consultados verificaram a presença de linkage.

Acredita-se que a identificação de marcadores (polimorfismos funcionais) em genes que sinalizam para uma maior ou menor atividade de um determinado sistema regulatório poderia estar associado ao maior risco do desenvolvimento de $\mathrm{HA}^{26}$. $\mathrm{O}$ gene receptor do sistema $\beta_{2}$ adrenérgico (ADRB2) é um dos genes candidatos que mais atenção tem solicitado dos pesquisadores. É sabido que, dentre outras funções, o sistema nervoso simpático controla a homeostase da PA exercendo forte influência sobre o débito cardíaco e o tônus vascular ${ }^{27}$. Assim, tendo em consideração a importância fisiológica reguladora do gene ADBR2, algumas variantes funcionais poderiam estar associadas a origem da $\mathrm{HA}^{27}$. Alguns estudos procuraram verificar associação entre os polimorfismos do gene ADBR2 e a HA ${ }^{27.30}$, contudo, os resultados são controversos. Villares et $\mathrm{al}^{30}$ encontraram associação significativa entre o polimorfismo Gln27Glu e a HA em obesos mórbidos e Ge et al ${ }^{28}$ obtiveram os mesmos resultados entre os polimorfismos Arg16Gly e Gln27Glu e a HA estágio 1l. Porém, Kato et $\mathrm{al}^{27} \mathrm{e}$ Tomaszewski et al ${ }^{29}$ não obtiveram os mesmos resultados nesses e em outros polimorfismos 
Quadro 2. Metodologia e principais resultados dos estudos de associação entre genes candidatos e hipertensão arterial.

\begin{tabular}{|c|c|c|c|c|c|}
\hline Autor ${ }^{\text {ref }}$, País & Propósito & Amostra & $\begin{array}{c}\text { Genes } \\
\text { candidatos }\end{array}$ & Principais resultados & Conclusões \\
\hline $\begin{array}{l}\text { Mettimano } \\
\text { et al } \\
\text { Itália }\end{array}$ & $\begin{array}{l}\text { Verificar associa- } \\
\text { ção entre os ale- } \\
\text { los CCR2 e CCR5 } \\
\text { com os níveis de } \\
\text { PA em indivíduos } \\
\text { hipertensos }\end{array}$ & $\begin{array}{c}118 \text { indivíduos } \\
\text { com HA estágio } \\
\text { I e II } \\
900^{7} \text { e } 28 \text { 우 } \\
\text { (27-54 anos) }\end{array}$ & $\begin{array}{l}\text { CCR2 } \\
\text { (OMIM } \\
601267) \\
\text { CCR5 } \\
\text { (OMIM } \\
601373)\end{array}$ & $\begin{array}{c}\text { Não foi observada } \\
\text { associação significati- } \\
\text { va entre CCR2 e a PA } \\
\text { Associação } \\
\text { significativa } \\
\text { entre CCR5 e a PAS }\end{array}$ & $\begin{array}{c}\text { Os resultados } \\
\text { evidenciam a } \\
\text { influência do gene CCR5 no } \\
\text { estabelecimento dos níveis } \\
\text { da PA }\end{array}$ \\
\hline $\begin{array}{l}\text { Barbalic } \\
\text { et al }{ }^{34} \\
\text { Escócia }\end{array}$ & $\begin{array}{l}\text { Verificar asso- } \\
\text { ciação entre os } \\
\text { polimorfismos } \\
\text { de três genes do } \\
\text { sistema renina } \\
\text { angiotensina } \\
\text { e o desenvolvi- } \\
\text { mento da HA }\end{array}$ & 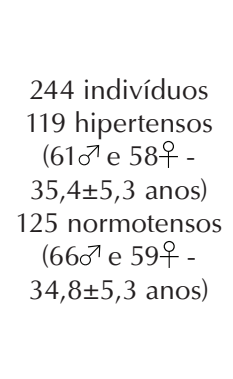 & $\begin{array}{c}\text { ACE } \\
\text { (OMIM } \\
106180) \\
\text { AGT } \\
\text { (OMIM } \\
\text { 106150) } \\
\text { AT1R } \\
\text { (OMIM } \\
\text { 106165) }\end{array}$ & $\begin{array}{l}\text { Somente os polimor- } \\
\text { fismos do gene ACE } \\
\text { apresentaram associa- } \\
\text { ção significativa com } \\
\text { a HA }\end{array}$ & $\begin{array}{l}\text { Os resultados evidenciam a } \\
\text { influência do gene ACE na } \\
\text { susceptibilidade da HA }\end{array}$ \\
\hline $\begin{array}{l}\text { Wang et } \mathrm{al}^{36} \\
\text { China }\end{array}$ & $\begin{array}{l}\text { Verificar asso- } \\
\text { ciação entre os } \\
\text { polimorfismos no } \\
\text { gene } \\
\text { GRK4 e a HAP }\end{array}$ & $\begin{array}{l}993 \text { indivíduos } \\
503 \text { hipertensos } \\
\left(262 \sigma^{7} \text { e } 241 \text { 우 - }\right. \\
53,5 \pm 9,3 \text { anos }) \\
490 \text { normotensos } \\
\text { (257ð e } 233 \text { 우 - } \\
53,5 \pm 9,2 \text { anos })\end{array}$ & $\begin{array}{c}\text { GRK4 } \\
\text { (OMIM } \\
\text { 137026) } \\
\text { polimorfismos } \\
\text { R65L, A142V e } \\
\text { A486V }\end{array}$ & $\begin{array}{l}\text { Associação significati- } \\
\text { va entre a variante do } \\
\text { alelo A486V e a HAP }\end{array}$ & $\begin{array}{c}\text { Os resultados encontrados } \\
\text { na população chinesa vão de } \\
\text { encontro aos encontrados na } \\
\text { população italiana e austra- } \\
\text { liana, indicando a influência } \\
\text { do gene } \\
\text { GRK4 na HAP }\end{array}$ \\
\hline $\begin{array}{l}\text { Ge et } \mathrm{al}^{28} \\
\text { China }\end{array}$ & $\begin{array}{l}\text { Verificar asso- } \\
\text { ciação entre os } \\
\text { polimorfismos do } \\
\text { gene } \\
\text { ADRB2 e a HA } \\
\text { estágio II }\end{array}$ & 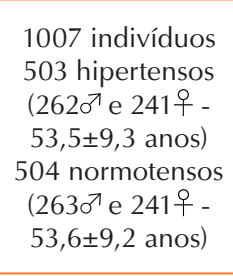 & $\begin{array}{c}\text { ADRB2 } \\
\text { (OMIM } \\
\text { 109690) } \\
\text { polimorfismos } \\
\text {-47CT, } \\
\text { Arg16Gly e } \\
\text { Gln27Glu }\end{array}$ & $\begin{array}{l}\text { Associação significati- } \\
\text { va entre } \\
\text { os polimorfismos } \\
\text { Arg16Gly } \\
\text { e GIn27Glu com a HA }\end{array}$ & $\begin{array}{c}\text { Os resultados sugerem que os } \\
\text { polimorfismos Gly16 e Gln } 27 \\
\text { do gene ADRB2 evidenciam } \\
\text { um aumento no risco para } \\
\text { a HA } \\
\text { estágio II }\end{array}$ \\
\hline $\begin{array}{l}\text { Gu et } \mathrm{al}^{38} \\
\text { China }\end{array}$ & $\begin{array}{l}\text { Verificar asso- } \\
\text { ciação entre os } \\
\text { polimorfismos do } \\
\text { gene } \\
\text { CYP11B2 e a HA } \\
\text { estágio II }\end{array}$ & $\begin{array}{l}1006 \text { indivíduos } \\
503 \text { hipertensos } \\
\left(262 \sigma^{\top} \text { e } 241 \text { 우 - }\right. \\
53,5 \pm 9,3 \text { anos }) \\
503 \text { normotensos } \\
\text { (262ð e } 241 \text { 우 - } \\
53,6 \pm 9,1 \text { anos })\end{array}$ & $\begin{array}{c}\text { CYP11B2 } \\
\text { (OMIM } \\
\text { 124080) } \\
\text { polimorfismos } \\
\text {-344T, Lys173 } \\
\text { e IC-conver- } \\
\text { sora do gene } \\
\text { CYP11B2 }\end{array}$ & $\begin{array}{l}\text { Associação } \\
\text { significativa entre } \\
\text { os polimorfismos } \\
\text { Lys173, IC e a HA } \\
\text { nas mulheres }\end{array}$ & $\begin{array}{c}\text { Os resultados sugerem que os } \\
\text { polimorfismos Lys173 e } \\
\text { IC-conversora do gene } \\
\text { CYP11B2 evidenciam um } \\
\text { aumento no risco para a } \\
\text { HA estágio II somente nas } \\
\text { mulheres }\end{array}$ \\
\hline
\end{tabular}




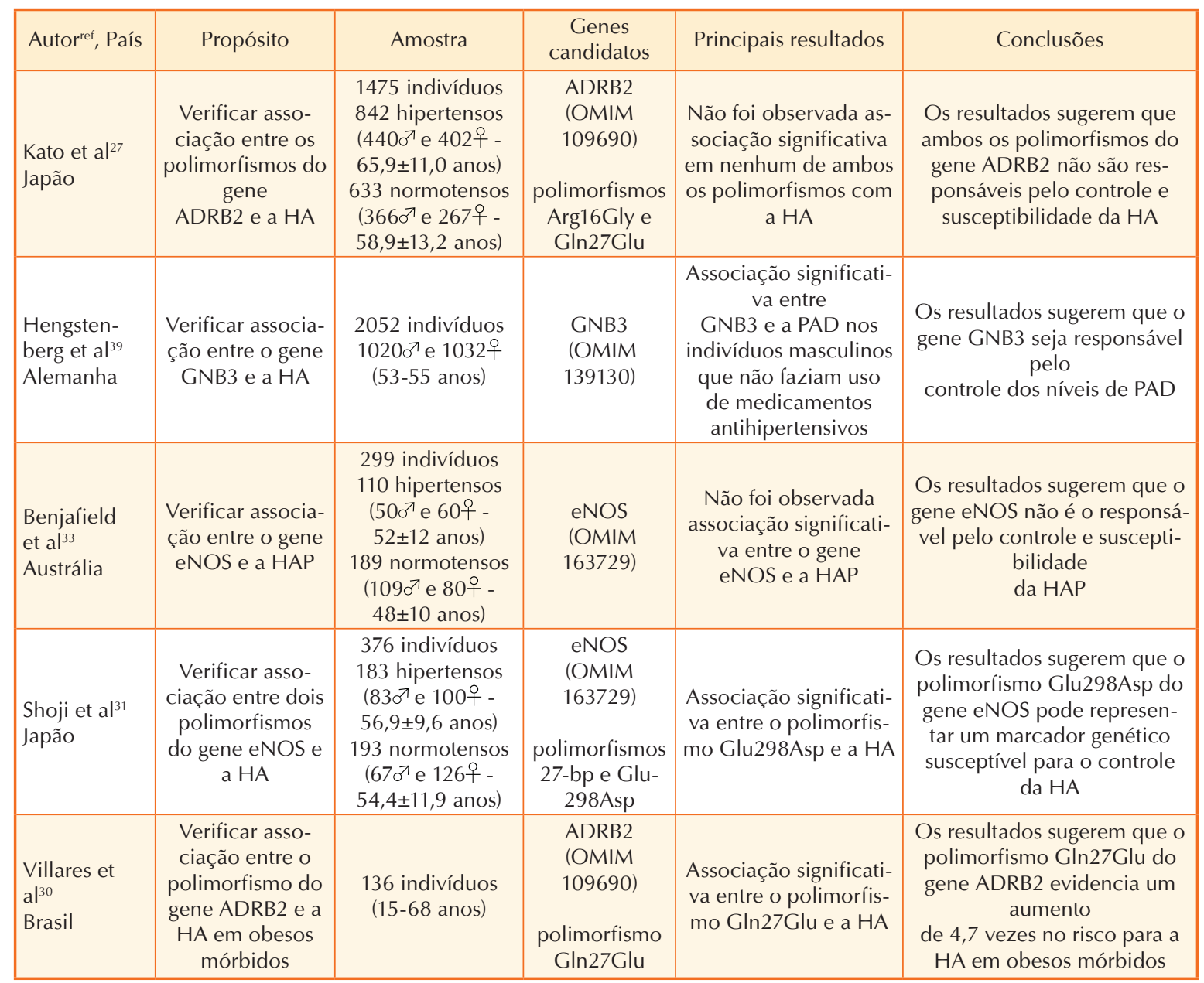

PA: pressão arterial, HA: hipertensão arterial, OMIM: Online Mendelian Inheritance in Man, PAS: pressão arterial sistólica, HAP: hipertensão arterial primária, PAD: pressão arterial diastólica.

do gene ADBR2. Outros genes candidatos estudados são os das enzimas conversoras de óxido nítricosintase endotelial (eNOS), responsáveis pela síntese do óxido nítrico, um importante regulador da PA. A anulação do gene eNOS propicia variabilidade da PA e a HA. Shoji et a ${ }^{131}$ verificaram que o polimorfismo Glu298Asp apresentou associação significativa com a hipertensão. Zhao et $\mathrm{al}^{32}$ e Benjafield et $\mathrm{al}^{33}$ não conseguiram encontrar tal associação em polimorfismos distintos. Igualmente importante na regulação dos valores da PA, o sistema renina-angiotensina caracteriza-se por um complexo sistema hormonal, cujo papel fundamental está relacionado com a PA e a homeostasia hidroeletrolítica no organismo. Barbalic et $\mathrm{a}^{34}$ verificaram que dos três genes envolvidos nesse sistema (ACE, AGT, AT1R), somente os polimorfismos do gene ACE apresentaram associação significativa com a HA.

\section{CONSIDERAÇÕES FINAIS}

Conclui-se que a PA é um fenótipo complexo, de natureza altamente poligênica, independentemente da relevância dos fatores ambientais. A utilização de amostras de diferentes países e continentes evidencia que na variação fenotípica total, os fatores genéticos explicam entre $14-68 \%$ da PAS e 6-62\% da PAD. Os resultados de linkage salientam sobretudo a presença de regiões candidatas pela regulação nos valores da PAS nos cromossomas 2, 5, 6, 15 e 17. Os principais genes candidatos na regulação da PA (ADRB2, eNOS) têm mostrado resultados díspares na associação com a hipertensão.

Os resultados da pesquisa já efetuada não são ainda suficientes para identificação precisa dos genes e seus variantes responsáveis pela HA. Ainda está distante de ser esclarecida a sua base genética e interações com diversos fatores ambientais originadores da variação populacional e individual. Contudo, novas tecnologias de microarrays e estratégias de association mapping sugerem novos desafios à pesquisa sobre essa doença complexa, cuja importância, em termos de saúde pública e qualidade de vida, é muito relevante para se continuar no 
seu rastro. Há também que adicionar pesquisa de epidemiologia analítica com ensaios clínicos randomizados para se verificar a resposta de variantes genéticas relevantes ao efeito de agentes ambientais como o exercício físico e a alimentação.

\section{REFERÊNCIAS BIBLIOGRÁFICAS}

1. JNC-7. The Seventh Report of the Joint National Committee on Prevention, Detection, Evaluation, and Treatment of High Blood Pressure. The JNC 7 Report. Hypertension 2003;42(6):1206-1252.

2. AHA. Heart Disease and Stroke Statistics - 2008 Update. A Report From the American Heart Association Statistics Committee and Stroke Statistics Subcommittee. Circulation 2008;117:25-146.

3. Gonçalves LM. Genetic markers of hypertension: what will the future bring? Rev Port Cardiol 2002;21(1):39-43.

4. Gu C, Borecki I, Gagnon J, Bouchard C, Leon AS, Skinner JS, et al. Familial resemblance for resting blood pressure with particular reference to racial differences: preliminary analyses from the HERITAGE Family Study. Hum Biol 1998;70(1):77-90.

5. Li JK, Ng MC, So WY, Chiu CK, Ozaki R, Tong PC, et al. Phenotypic and genetic clustering of diabetes and metabolic syndrome in Chinese families with type 2 diabetes mellitus. Diabetes Metab Res Rev 2006;22(1):46-52.

6. Mills GW, Avery PJ, McCarthy MI, Hattersley AT, Levy JC, Hitman GA, et al. Heritability estimates for beta cell function and features of the insulin resistance syndrome in UK families with an increased susceptibility to type 2 diabetes. Diabetologia 2004;47(4):732-738.

7. Freeman MS, Mansfield MW, Barrett JH, Grant PJ. Heritability of features of the insulin resistance syndrome in a community-based study of healthy families. Diabet Med 2002;19(12):994-999.

8. Livshits G, Gerber LM. Familial factors of blood pressure and adiposity covariation. Hypertension 2001;37(3):928-935.

9. Saunders CL, Gulliford MC. Heritabilities and shared environmental effects were estimated from household clustering in national health survey data. J Clin Epidemiol 2006;59(11):1191-1198.

10. Butte NF, Comuzzie AG, Cole SA, Mehta NR, Cai G, Tejero M, et al. Quantitative genetic analysis of the metabolic syndrome in Hispanic children. Pediatr Res 2005;58(6):1243-1248.

11. North KE, Howard BV, Welty TK, Best LG, Lee ET, Yeh JL, et al. Genetic and environmental contributions to cardiovascular disease risk in American Indians: the strong heart family study. Am J Epidemiol 2003;157(4):303-314.

12. Liu XQ, Hanley AJ, Paterson AD. Genetic analysis of common factors underlying cardiovascular diseaserelated traits. BMC Genet 2003;4 Suppl 1:S56.

13. McQueen MB, Bertram L, Rimm EB, Blacker D, Santangelo SL. A QTL genome scan of the metabolic syndrome and its component traits. BMC Genet 2003;4 Suppl 1:S96.
14. Martin LJ, North KE, Dyer T, Blangero J, Comuzzie AG, Williams J. Phenotypic, genetic, and genome-wide structure in the metabolic syndrome. BMC Genet 2003;4 Suppl 1:S95.

15. Camp NJ, Hopkins PN, Hasstedt SJ, Coon H, Malhotra A, Cawthon RM, et al. Genome-wide multipoint parametric linkage analysis of pulse pressure in large, extended utah pedigrees. Hypertension 2003;42(3):322-328.

16. Cheng LS, Davis RC, Raffel LJ, Xiang AH, Wang $\mathrm{N}$, Quinones $\mathrm{M}$, et al. Coincident linkage of fasting plasma insulin and blood pressure to chromosome $7 \mathrm{q}$ in hypertensive hispanic families. Circulation 2001;104(11):1255-1260.

17. Hsueh WC, Mitchell BD, Aburomia R, Pollin T, Sakul $\mathrm{H}$, Gelder Ehm M, et al. Diabetes in the Old Order Amish: characterization and heritability analysis of the Amish Family Diabetes Study. Diabetes Care 2000;23(5):595-601.

18. Levy D, DeStefano AL, Larson MG, O’Donnell CJ, Lifton RP, Gavras H, et al. Evidence for a gene influencing blood pressure on chromosome 17. Genome scan linkage results for longitudinal blood pressure phenotypes in subjects from the framingham heart study. Hypertension 2000;36(4):477-483.

19. An P, Rice T, Gagnon J, Borecki IB, Perusse L, Leon AS, et al. Familial aggregation of resting blood pressure and heart rate in a sedentary population: the HERITAGE Family Study. Health, Risk Factors, Exercise Training, and Genetics. Am J Hypertens 1999;12(3):264-270.

20. Chien KL, Hsu HC, Chen WJ, Chen MF, Su TC, Lee YT. Familial aggregation of metabolic syndrome among the Chinese: Report from the Chin-Shan community family study. Diabetes Res Clin Pract 2007;76(3):418-424.

21. Ng MC, So WY, Lam VK, Cockram CS, Bell GI, Cox NJ, et al. Genome-wide scan for metabolic syndrome and related quantitative traits in Hong Kong Chinese and confirmation of a susceptibility locus on chromosome 1q21-q25. Diabetes 2004;53(10):2676-2683.

22. Jee SH, Suh I, Won SY, Kim MY. Familial correlation and heritability for cardiovascular risk factors. Yonsei Med J 2002;43(2):160-164.

23. Rotimi CN, Cooper RS, Cao G, Ogunbiyi O, Ladipo $\mathrm{M}$, Owoaje E, et al. Maximum-likelihood generalized heritability estimate for blood pressure in Nigerian families. Hypertension 1999;33(3):874-878.

24. Knuiman MW, Divitini ML, Welborn TA, Bartholomew HC. Familial correlations, cohabitation effects, and heritability for cardiovascular risk factors. Ann Epidemiol 1996;6(3):188-194.

25. Krushkal J, Ferrell R, Mockrin SC, Turner ST, Sing $\mathrm{CF}$, Boerwinkle E. Genome-wide linkage analyses of systolic blood pressure using highly discordant siblings. Circulation 1999;99(11):1407-1410.

26. Barreto-Filho JA, Krieger JE. Genética e hipertensão arterial: Conhecimento aplicado à prática clínica? Rev Soc Cardiol Estado de São Paulo 2003;13(1):46-55. 
27. Kato N, Sugiyama T, Morita H, Kurihara H, Sato T, Yamori $Y$, et al. Association analysis of beta(2)-adrenergic receptor polymorphisms with hypertension in Japanese. Hypertension 2001;37(2):286-292.

28. Ge D, Huang J, He J, Li B, Duan X, Chen R, et al. Beta2-Adrenergic receptor gene variations associated with stage-2 hypertension in northern Han Chinese. Ann Hum Genet 2005;69(Pt 1):36-44.

29. Tomaszewski M, Brain NJ, Charchar FJ, Wang WY, Lacka B, Padmanabahn S, et al. Essential hypertension and beta2-adrenergic receptor gene: linkage and association analysis. Hypertension 2002;40(3):286-291.

30. Villares SM, Mancini MC, Gomez S, Charf AM, Frazzanatto E, Halpern A. Associação entre polimorfismo Gln27Glu do receptor beta-2 adrenérgico e hipertensão arterial sistêmica em obesos mórbidos. Arq Bras Endocrinol Metab 2000;44(1):72-80.

31. Shoji M, Tsutaya S, Saito R, Takamatu H, Yasujima M. Positive association of endothelial nitric oxide synthase gene polymorphism with hypertension in northern Japan. Life Sci 2000;66(26):2557-2562.

32. Zhao Q, Su SY, Chen SF, Li B, Gu DF. Association study of the endothelial nitric oxide synthase gene polymorphisms with essential hypertension in northern Han Chinese. Chin Med J 2006;119(13):1065-1071.

33. Benjafield AV, Morris BJ. Association analyses of endothelial nitric oxide synthase gene polymorphisms in essential hypertension. Am J Hypertens 2000;13(9):994-998.

34. Barbalic M, Skaric-Juric T, Cambien F, Barbaux S, Poirier O, Turek S, et al. Gene polymorphisms of the renin-angiotensin system and early development of hypertension. Am J Hypertens 2006;19(8):837-842.
35. Mettimano M, Specchia ML, La Torre G, Bruno A, Ricciardi G, Savi L, et al. Blood pressure regulation by CCR genes. Clin Exp Hypertens 2006;28(7):611-618.

36. Wang Y, Li B, Zhao W, Liu P, Zhao Q, Chen S, et al. Association study of $G$ protein-coupled receptor kinase 4 gene variants with essential hypertension in northern Han Chinese. Ann Hum Genet 2006;70:778-783.

37. Danoviz ME, Pereira AC, Mill JG, Krieger JE. Hypertension, obesity and GNB 3 gene variants. Clin Exp Pharmacol Physiol 2006;33(3):248-252.

38. Gu D, Ge D, He J, Li B, Chen J, Liu D, et al. Haplotypic analyses of the aldosterone synthase gene CYP11B2 associated with stage-2 hypertension in northern Han Chinese. Clin Genet 2004;66(5):409-416.

39. Hengstenberg C, Schunkert H, Mayer B, Doring A, Lowel H, Hense HW, et al. Association between a polymorphism in the G protein beta3 subunit gene (GNB3) with arterial hypertension but not with myocardial infarction. Cardiovasc Res 2001;49(4):820-827.

\section{Endereço para correspondência}

José António Ribeiro Maia

Universidade do Porto -

Faculdade de Desporto.

Laboratório de Cineantropometria e Gabinete de Estatística Aplicada.

Rua Dr. Plácido Costa, 91 - 4200-450

Porto - Portugal.

E-mail: jmaia@fade.up.pt 